\title{
Seasonal Variation of Severe Hypoglycemia in Hospitalized Patients 60 years of Age or Older Presenting to an Emergency Center Hospital between 2004 and 2010
}

\author{
Tomoko Hashimoto, Ai Morita, Yo Hashimoto, Fukuko Yagami, Kazutaka Sakamoto, \\ Masahiko Owada, Takashi Sugawara and Minoru Kawamura
}

\begin{abstract}
Objective To investigate the seasonal variation of severe hypoglycemia in hospitalized elderly patients. Methods Among the patients hospitalized in our department between 2004 and 2010, we analyzed the records of 67 patients who required emergency admission for severe hypoglycemia and were aged 60 years or older. Comparisons were made between those admitted during the warm season (April-September) and those in the cold season (October-March).

Patients The mean age of the 67 patients was $76 \pm 8$ years, including 45 men and 22 women. Twenty-four patients were admitted in the warm season and 43 patients were admitted in the cold season, with the average annual number being $3.4 \pm 1.9$ and $6.1 \pm 2.8$, respectively $(\mathrm{p}<0.05)$.

Results Admissions for patients taking insulin showed no significant difference between the warm and cold season. In contrast, significantly fewer patients taking oral hypoglycemic agents were admitted in the warm season than in the cold season ( 5 vs. $22, \mathrm{p}<0.05$ ). Among them, 26 patients $(96 \%)$ were taking sulfonylurea, and anorexia associated with acute infections was the main cause of severe hypoglycemia. In the warm season, all of the patients were discharged without complications, while 8 patients had complications in the cold season.

Conclusion A seasonal variation regarding hospitalization was observed for severe hypoglycemia among the patients 60 years of age or older, with a higher incidence in the cold season than the warm season, and anorexia related to infections in patients taking sulfonylureas was responsible for this variation. Accordingly, careful management of acute illness is needed for patients using sulfonylureas, especially during the cold season.
\end{abstract}

Key words: severe hypoglycemia, seasonal variation, elderly, sulfonylurea, anorexia, infection

(Intern Med 52: 2721-2726, 2013)

(DOI: 10.2169/internalmedicine.52.0495)

\section{Introduction}

Hypoglycemia is a common emergency condition (1) which remains a limiting factor for glycemic control in patients with diabetes (2).

Intensive anti-diabetic therapy which targets near normoglycemia has been demonstrated to reduce the risk of microvascular complications (3-5) and macrovascular complications (6). Accordingly, intensive therapy became widely used in 2000, and consequently there were many episodes of severe hypoglycemia, especially among elderly patients. A longitudinal population-based study performed in Germany showed an increase of severe hypoglycemia among elderly patients between the two periods of 1997-2000 and 2007-2010 (7), although this increase may have been due, in part, to the larger number of elderly diabetic patients (8). Careful management is necessary to prevent severe hypoglycemic episodes in elderly diabetic patients. A possible seasonal variation of such episodes, should therefore be consid- 


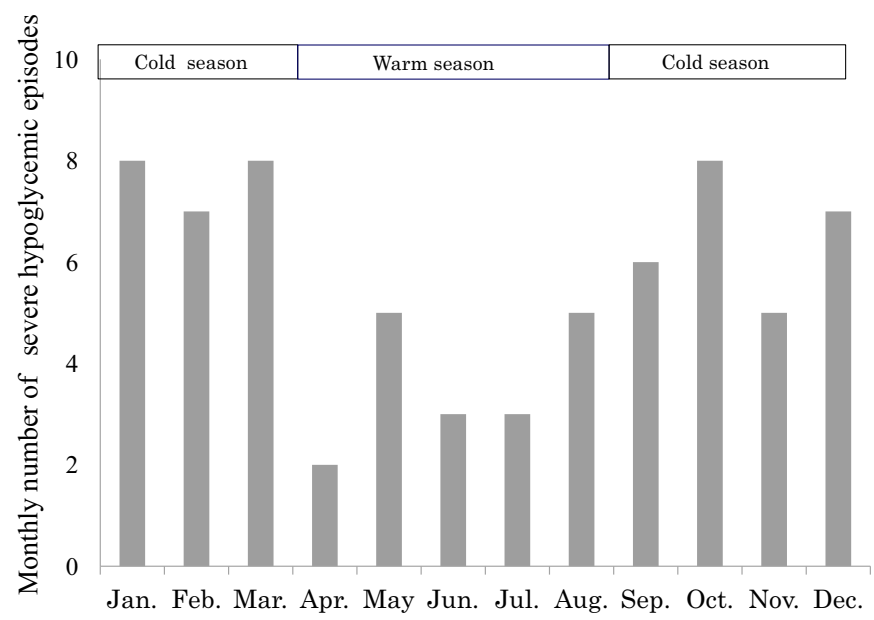

Figure 1. Monthly number of elderly patients with severe hypoglycemia requiring emergency admission between 2004 and 2010.

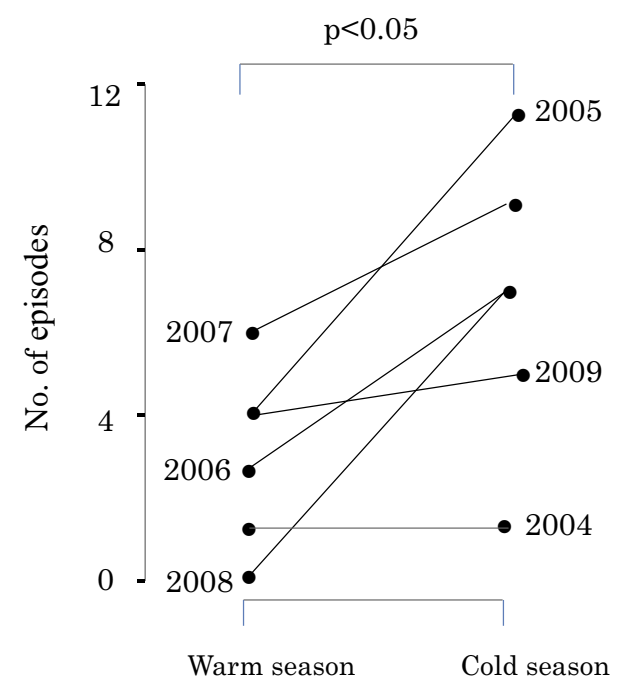

Figure 2. Annual number of elderly patients with severe hypoglycemia admitted during the warm season (April to September) and the cold season (October to March) between April 2004 and September 2009 stratified by the fiscal year. There was a significant difference between the warm season and the cold season $(p<0.05$ according to the Wilcoxon signed-rank test).

ered. In Japan, several diseases show seasonal variation. For example, myocardial infarction (9) and stroke (10) are more frequent in the winter than in the summer, while blood pressure (11), cholesterol (12), and hemoglobin A $1 \mathrm{C}$ [HbA1C (13)] levels are all higher in the winter compared to in the summer. However, little is known about the seasonal variation of severe hypoglycemia. Accordingly, the present study was undertaken to investigate whether severe hypoglycemia shows seasonal variation by analyzing the database of elderly patients hospitalized in our department.

\section{Materials and Methods}

Our department manages patients who are admitted to
Table 1. Antidiabetic Therapy of Elderly Patients with Severe Hypoglycemia in the Warm and Cold Seasons

\begin{tabular}{|c|c|c|}
\hline & Warm season (24) & Cold season (43) \\
\hline Insulin & 11 & 13 \\
\hline 1-2 times daily & 7 & 6 \\
\hline$\geq 3$ times daily & 4 & 7 \\
\hline OHA & 5 & $22 *$ \\
\hline Sulfonylureas & 5 & $21^{*}$ \\
\hline Alpha-glycosidase inhibitors & 0 & 9 \\
\hline Pioglitazone & 3 & 3 \\
\hline Biguanides & 0 & 1 \\
\hline
\end{tabular}

No antidiabetic therapy

8

8

$*_{\mathrm{p}}<0.05$ compared with the warm season by the chi-square test.

OHA: oral hypoglycemic agents

Iwate Prefectural Central Hospital with diseases related to diabetes mellitus including hypoglycemia. By reviewing the discharge summaries of 4,032 patients admitted to our department between January, 2004 and December, 2010, we selected 74 patients who satisfied the following three criteria: "severe hypoglycemia", "emergency admission", and "age $\geqq 60$ years old". Severe hypoglycemia was defined as a symptomatic event requiring treatment with intravenous glucose and was confirmed by a blood glucose level of less than $60 \mathrm{mg} / \mathrm{dL}$. After the exclusion of 5 patients with incomplete medical records and 2 patients who did not meet the criteria for severe hypoglycemia, the remaining 67 patients were subjected to further analysis. The presence of infection just before admission was assessed based on fever, chills, and respiratory or gastrointestinal symptoms. The HbA1C (\%) data were expressed as National Glycohemoglobin Standardization Program equivalent values (14). The warm season was defined as the season from April to Sep- 
Table 2. Causes of Severe Hypoglycemia in Patients Using Sulfonylureas or Insulin

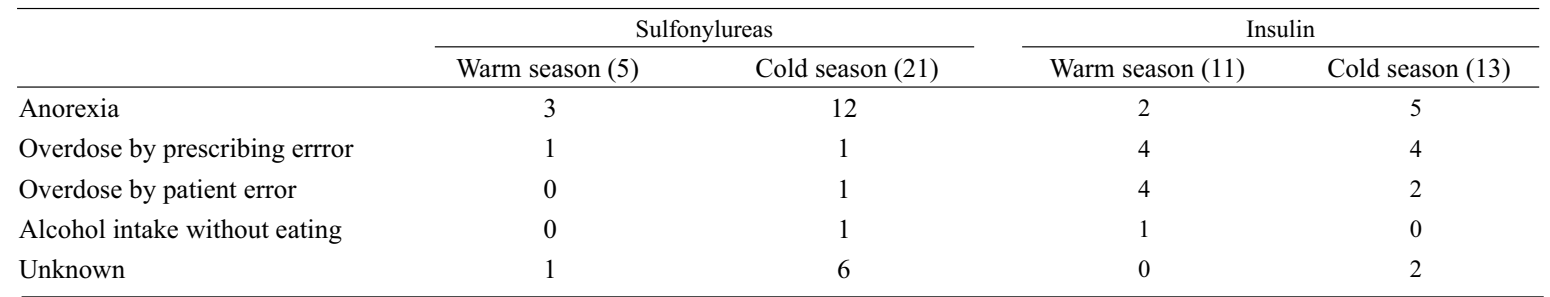

tember, while the cold season was from January to March and October to December. The results were expressed as the mean $\pm \mathrm{SD}$. Variables were compared between the two seasons by the Mann-Whitney U-test, Wilcoxon signed-rank test, or chi-squared test as appropriate. In all analyses, a probability (p) value of less than 0.05 was considered to indicate statistical significance.

Approval for this study was granted by the ethics committee of Iwate Prefectural Central Hospital and it was performed in accordance with the Helsinki Declaration.

\section{Results}

The 67 patients ( 45 men and 22 women) with severe hypoglycemia were a mean age of $76 \pm 8$ years, with a body mass index (BMI) of $21.8 \pm 3.5 \mathrm{~kg} / \mathrm{m}^{2}$, mean plasma glucose level of $24 \pm 14 \mathrm{mg} / \mathrm{dL}$, and $\mathrm{HbA} 1 \mathrm{C}$ of $6.3 \pm 1.6 \%$. Among them, 24 patients were taking insulin (with/without oral hypoglycemic agents), 27 patients were on oral agents alone, and the remaining 16 patients were not taking any antidiabetic agents. Excluding these 16 patients, the mean plasma glucose level was $24 \pm 14 \mathrm{mg} / \mathrm{dL}$ and $\mathrm{HbA1C}$ was $7.2 \pm 2.1 \%$. There were no significant differences in the baseline characteristics between men and women.

Fig. 1 shows the monthly number of patients hospitalized with severe hypoglycemia during the study period. The highest peaks were observed in January, March, and October, while the lowest number of admissions was in April. Twenty-four patients were admitted in the warm season and 43 were admitted in the cold season.

The number of patients admitted with severe hypoglycemia was compared between the warm season (April to September) and the cold season (January to March plus October to December) for each calendar year from 2004 to 2010. The average number of admissions was lower in the warm season than in the cold season $(3.4 \pm 1.9$ vs. $6.1 \pm 2.8)$, and the difference was significant $(\mathrm{p}<0.05)$. However, the cold season was divided into October to December of one year and January to March of the following year in this analysis. To avoid any division of the cold season, the analysis was performed from the start of April 2004 to the end of September 2009. Fig. 2 shows the number of patients with severe hypoglycemia admitted during each warm and cold season as stratified by the fiscal year. The average number of admissions was still lower in the warm season than in the cold season $(3.0 \pm 2.2$ vs. $6.7 \pm 3.4)$, and the difference was again
Table 3. Causes of Severe Hypoglycemia in 16 Patients Not Receiving Antidiabetic Therapy

\begin{tabular}{lcc}
\hline & Warm season (8) & Cold season (8) \\
\hline Chronic anorexia & 4 & 2 \\
Alcohol-induced hypoglycemia & 3 & 2 \\
Dumping syndrome & 1 & 1 \\
Reactive hypoglycemia & 0 & 1 \\
Drug-induced hypoglycemia & 0 & 1 \\
Suicide attempt & 0 & 1 \\
\hline
\end{tabular}

significant $(\mathrm{p}<0.05)$.

On the other hand, the average number of ambulance cases was $2,434 \pm 261$ during each warm season and 2,444 \pm 250 during each cold season by calendar year, thus indicating no significant difference between the two seasons. The Meteorological Agency records indicated that the mean temperature was $17.8^{\circ} \mathrm{C}$ for the warm season and $6.7^{\circ} \mathrm{C}$ for the cold season in the local area (Morioka) during the study period.

There were no significant differences between the warm season and the cold season with respect to the male/female ratio $(14 / 10$ vs. $31 / 12)$, age $(77 \pm 7$ vs. $75 \pm 9$ years), BMI $\left(21.3 \pm 2.6\right.$ vs. $\left.22.1 \pm 4.0 \mathrm{~kg} / \mathrm{m}^{2}\right)$, plasma glucose level $(24 \pm 14$ vs. $24 \pm 14 \mathrm{mg} / \mathrm{dL}$ ), and $\mathrm{HbA1C}(6.7 \pm 2.5$ vs. $6.8 \pm 1.8 \%)$. Table 1 shows the treatment of diabetes for patients stratified between the warm and cold seasons. There was no significant difference between the seasons for patients taking insulin or patients not receiving any anti-diabetic therapy. However, the seasonal variation was significant for patients on oral hypoglycemic therapy, and there were significantly more patients taking sulfonylureas who developed hypoglycemia during the cold season.

Table 2 lists the causes of severe hypoglycemia in the 26 patients taking sulfonylureas and in the 24 patients taking insulin. Fifteen (58\%) patients of the 26 patients taking sulfonylureas had appetite loss, and 2 patients during the warm season and 8 patients during the cold season had infections. Among the 24 subjects taking insulin, loss of appetite was noted in 2 patients during the warm season and 5 patients during the cold season. Table 3 lists the causes of severe hypoglycemia in the 16 patients not receiving any anti-diabetic therapy; alcohol-induced hypoglycemia and chronic anorexia were the main causes in these patients.

All of the patients admitted during the warm season were 
Table 4. Profiles of 8 Patients with Serious Complications among Those Developing Severe Hypoglycemia in the Cold Season

\begin{tabular}{ccccccc}
\hline $\begin{array}{c}\text { Age } \\
\text { (years) }\end{array}$ & Sex & $\begin{array}{c}\text { BMI } \\
\left(\mathrm{kg} / \mathrm{m}^{2}\right)\end{array}$ & Treatment of diabetes & Complications & Hospitalization \\
(days)
\end{tabular}

SU: sulfonylurea

discharged without any complications, while $8 / 43$ patients (19\%) had complications during the cold season. Table 4 shows the profile of these 8 patients. Two very old patients died of pneumonia, and two patients with hypoglycemic encephalopathy were transferred to other hospitals for rehabilitation. The remaining 4 patients had epilepsy, pneumonia, cerebral infarction, and angina pectoris, respectively, but they were eventually discharged without any sequelae.

\section{Discussion}

The present retrospective survey showed that significantly more elderly patients required emergency admission for severe hypoglycemia during the cold season than during the warm season; there was a, 1.8-fold difference, thus suggesting a seasonal variation to exist in the prevalence of severe hypoglycemia. Seasonal variation of severe hypoglycemia among children has been reported previously, with a peak in the spring (15). To our knowledge, however, this was the first investigation into seasonal variation of severe hypoglycemia in the elderly. Our findings suggested that the management of hypoglycemia requires additional care in the cold season.

The present study also indicated that patients taking sulfonylureas were mainly affected by the seasonal variation, because these patients had a significantly higher frequency of hypoglycemic episodes in the cold season $(n=21)$ than in the warm season $(n=5)$. Nagayama et al. reported that $96 \%$ of all patients hospitalized with hypoglycemic coma who were on oral therapy for diabetes were taking sulfonylureas (16), and other reports $(7,17,18)$ have also indicated that sulfonylurea therapy is associated with severe hypoglycemia. Fifteen out of 26 patients (58\%) taking sulfonylureas had a loss of appetite which was predominantly caused by an infection, thus suggesting that infection may be the main reason for the seasonal variation of hypoglycemic episodes. Although 6 cold season patients using sulfonylureas were categorized as "unknown cause" in Table 2 because there was no relevant data in their medical records; the majority of patients probably had appetite loss. Viral infections such as those due to influenza virus (19) and norovirus (20) are prevalent in the cold season, resulting in appetite loss and the risk of severe hypoglycemia if patients do not modify their sulfonylurea regimens. Therefore, correct management is important when patients taking sulfonylureas develop an acute illness. In addition to hypoglycemia, attention must be also paid to the possibility that the acute illness may conversely cause hyperglycemic coma associated with dehydration, especially in elderly patients.

What is the reason that patients taking insulin and those with no diabetic therapy showed no seasonal variation of severe hypoglycemia?

The cost for the self-measurement of blood glucose is covered by the national health insurance plan in Japan for patients using insulin, and thus they may have detected the hypoglycemia and accordingly followed countermeasures before the hypoglycemia became severe. Alternatively, patients using insulin may be better educated about diabetes than patients taking sulfonylureas (17), therefore those on insulin therapy coped better with the management of acute illness. The patients who were not on medication had only a few episodes of severe hypoglycemia (alcohol-induced hypoglycemia, chronic anorexia, etc.), so it remains unclear whether there is any seasonal variation in the hypoglycemic episodes observed in these patients.

According to Joslin's Diabetes Mellitus textbook (21), there is no generally accepted glucose concentration that defines hypoglycemia, but a venous glucose concentration between $45-60 \mathrm{mg} / \mathrm{dL}$ is strongly suggestive of hypoglycemia and levels below $45 \mathrm{mg} / \mathrm{dL}$ are usually indicative of important pathology. Although we adopted a plasma glucose level of $60 \mathrm{mg} / \mathrm{dL}$ as the cut-off point for hypoglycemia, other studies $(1,7,17)$ have adopted $50 \mathrm{mg} / \mathrm{dL}$ as the cut-off point. In fact, only two of our patients had plasma glucose levels above $50 \mathrm{mg} / \mathrm{dL}$. They were both using insulin and severe hypoglycemia occurred in August 2007 and January 2008 in one patient each. Even if we deleted the data for these patients, our conclusions would not differ.

Complications were only observed during the cold season. In $5(63 \%)$ of the 8 patients affected, the complications were pneumonia, cerebral infarction, and angina pectoris, which represent 3 of the 4 major causes of death in Japan 
(cancer, heart disease, cerebrovascular disease, and pneumonia). These 3 diseases have been reported to show seasonal variation and are more frequent in winter (22), which may explain the higher complication rate for patients with severe hypoglycemia in the cold season.

There were several limitations of the present study. First, the patients were all hospitalized for severe hypoglycemia in our department, thus no information was obtained about patients with severe hypoglycemia who were treated in the emergency room without admission or who were admitted to other departments because they had complications such as stroke or ischemic heart disease. Several emergency outpatient units have reported that hypoglycemic patients using insulin outnumber those taking sulfonylureas $(7,17,18)$, while the present study showed the reverse results for hospitalized patients. One study showed that the number of patients requiring hospitalization was significantly higher than the number discharged to home among hypoglycemic patients taking sulfonylureas (18), which are known to cause prolonged hypoglycemic coma, especially in the elderly. Second, the present study was performed in the Morioka region where the mean daily temperature is $17.8^{\circ} \mathrm{C}$ in the warm season and $6.7^{\circ} \mathrm{C}$ in the cold season (room temperature of $26^{\circ} \mathrm{C}$ and $20^{\circ} \mathrm{C}$, respectively) (23); the wide temperature difference between seasons may have influenced the seasonal variation of severe hypoglycemia. Accordingly, the seasonal variation of severe hypoglycemia should also be evaluated in different climates. Third, the annual number of patients admitted with severe hypoglycemia was comparatively small, although we could still observe a statistically significant difference between the warm season and the cold season over 7 years. The small annual number was due to the fact that study was undertaken at a single emergency center, and thus a multicenter investigation is recommended in the future.

In conclusion, we investigated the seasonal variation of hospitalized patients (aged $\geq 60$ years old) who were admitted to our department between 2004 and 2010 for severe hypoglycemia. We found a higher incidence of severe hypoglycemia during the cold season (October to March) than during the warm season (April to September). A loss of appetite related to acute infectious illnesses in patients on sulfonylurea therapy was main reason for the seasonal variation. Therefore, the careful management of acute illness seems to be an important factor for elderly patients taking sulfonylureas to avoid the onset of severe hypoglycemia.

\section{The authors state that they have no Conflict of Interest (COI).}

\section{References}

1. Su CC. Etiologies of acute hypoglycemia in a Taiwanese hospital emergency department. J Emer Med 30: 259-261, 2006.

2. Cryer PE. The barrier of hypoglycemia in diabetes. Diabetes 57: 3169-3176, 2008.

3. The Diabetes Control and Complications Trial Research Group.
The effect of intensive treatment of diabetes on the development and progression of long-term complications in insulin-dependent diabetes mellitus. N Engl J Med 329: 977-986, 1993.

4. Ohkubo Y, Kishikawa H, Araki E, et al. Intensive insulin therapy prevents the progression of diabetic microvascular complications in Japanese patients with non-insulin-dependent diabetes mellitus: a randomized prospective 6-year study. Diabetes Res Clin Prac 28: 103-117, 1995.

5. UK Prospective Diabetes Study (UKPDS) Group. Intensive blood glucose control with sulphonylureas or insulin compared with conventional treatment and risk of complications in patients with type 2 diabetes (UKPDS 33). Lancet 352: 837-853, 1998.

6. The Diabetes Control and Complications Trial/Epidemiology of Diabetes Interventions and Complications (DCCT/EDIC) Study Group. Intensive diabetes treatment and cardiovascular disease in patients with type 1 diabetes. N Engl J Med 353: 2643-2653, 2005.

7. Holstein A, Patzer OM, Machalke K, Holstein JD, Stumvoll M, Kovacs P. Substantial increase in incidence of severe hypoglycemia between 1997-2000 and 2007-2010. Diabetes Care 35: 972975, 2012.

8. King H, Aubert RE, Herman WE. Global burden of diabetes, 1995-2025. Diabetes Care 21: 1414-1431, 1998.

9. Sawanobori T, Komori S. Influence on seasonality of heart disease, particularly acute myocardial infarction. Chikyuu-Knakyou 8: 193-200, 2003 (in Japanese, Abstract in English).

10. Okada K, Yamagata S, Fukuda M, Iijima K, Kobayashi S. An epidemiological study of stroke in a geriatric community-With special reference to meteorological factors. Jpn J Geriat 32: 39-46, 1995 (in Japanese, Abstract in English).

11. Fujiwara $T$, Kawamura $M$, Nakajima J, Adachi $T$, Hiramori $K$. Seasonal differences in diurnal blood pressure of hypertensive patients living in a stable environmental temperature. J Hypertension 13: 1747-1752, 1995.

12. Kamezaki F, Sonoda S, Tomotsune Y, Yunaka H, Otsuji Y. Seasonal variation in serum lipid levels in Japanese workers. J Atheroscler Thromb 17: 638-643, 2010.

13. Isii $H$, Suzuki H, Baba T, Nakamura K, Watanabe T. Seasonal variation of glycemic control in type 2 diabetic patients. Diabetes Care 24: 1503, 2001.

14. Kashiwagi A, Kasuga M, Araki E, et al. International clinical harmonization of glycated hemoglobin in Japan: from Japan Diabetes Society of National Glycohemoglobin Standardization Program values. J Diabetes Invest 3: 39-40, 2012.

15. Baum JD, Kinmonth AL. Spring hypoglycaemia in diabetic children. Br Med J 280: 1227, 1980.

16. Nagayama K, Kakizawa K, Okawa Y, Morita H, Oki Y, Nakamura $\mathrm{H}$. Twenty-seven patients with hypoglycemic coma requiring hospitalization during oral hypoglycemic treatment. J Jpn Diab Soc 54: 271-276, 2011 (in Japanese, Abstract in English).

17. Katsumata K, Oiso Y, Nakamura J, et al. Prevalence and outcome of severe hypoglycemia at a hospital in Aichi Prefecture, based on a questionnaire survey. J Jpn Diab Soc 49: 251-257, 2006 (in Japanese, Abstract in English).

18. Kudo T, Moriyama T, Kakizaki Y, Kasai N. Study on the clinical features of emergency room cases of hypoglycemia. J Jpn Diab Soc 55: 316-321, 2012 (in Japanese, Abstract in English).

19. Azziz Baumgartner E, Dao CN, Nasreen S, et al. Seasonality, timing, and climate drivers of influenza activity worldwide. J Infect Dis 15: 838-846, 2012.

20. Wang J, Deng Z. Detection and forecasting of oyster norovirus outbreaks:recent advances and future perspectives. Mar Environ Res 80: 62-69, 2012.

21. Glaser B, Leibowitz G. Hypoglycemia. In: Joslin's Diabetes Mellitus. 14th ed. Kahn CR, Weir GC, King GL, et al, Eds. Lippncott Williams \& Wilkins, 2005: 1147-1175. 
Intern Med 52: 2721-2726, 2013 DOI: 10.2169/internalmedicine.52.0495

22. Ministry of Health, Labour and Welfare: The general condition of death statistics of heart disease-cerebrovascular disease; Vital statistics special report 2004. available: http//mhlw.go.jp/toukei/ saikin/hw/jinkou/tokusyu/sinno05/9.html (Accessed 1 January
2013).

23. Nakajima J, Kawamura M, Fujiwara T, Hiramori K. Body height is a determinant of seasonal blood pressure variation in patients with essential hypertension. Hypertens Res 23: 587-592, 2000.

(C) 2013 The Japanese Society of Internal Medicine http://www.naika.or.jp/imonline/index.html 